\title{
Testing fireproof materials in a combustion chamber
}

\author{
Petr Kulhavy ${ }^{1, a}$, Tomas Martinec ${ }^{1}$, Ondrej Novak ${ }^{1}$, Michal Petru ${ }^{1}$ and Pavel Srb ${ }^{1}$ \\ ${ }^{1}$ Institute for Nanomaterials, Advanced Technologies and Innovation, Technical University of Liberec, Studentská 2 , \\ 461 17, Liberec 1, Czech Republic
}

\begin{abstract}
This article deals with a prototype concept, real experiment and numerical simulation of a combustion chamber, designed for testing fire resistance some new insulating composite materials. This concept of a device used for testing various materials, providing possibility of monitoring temperatures during controlled gas combustion. As a fuel for the combustion process propane butane mixture has been used and also several kinds of burners with various conditions of inlet air (forced, free) and fuel flows were tested. The tested samples were layered sandwich materials based on various materials or foams, used as fillers in fire shutters. The temperature distribution was measured by using thermocouples. A simulation of whole concept of experimental chamber has been carried out as the non-premixed combustion process in the commercial final volume sw Pyrosim. The result was to design chamber with a construction suitable, according to the international standards, achieve the required values (temperature in time). Model of the combustion based on a stoichiometric defined mixture of gas and the tested layered samples showed good conformity with experimental results - i.e. thermal distribution inside and heat release rate that has gone through the sample.
\end{abstract}

\section{Introduction}

Fire safety is an inseparable aspect during the buildings design. One of the basic requirements especially for industrial buildings is dividing the building into fire zones, each other protected by fire partition structures, to prevent spreading of a potential fire and minimization looses [1]. Also in this sector, reduction of weight used material plays an important role. It is necessary to minimize weight of parts without affecting their functionality and safety - often even on the contrary with their improvement. In our case some light fireproof materials that are used in fast fire barriers (e.g. movable gate, blinds) have been tested. Their function is to create a thermal shield between place which should stay safe and cool even if they are affected by high temperature radiation and convection from a near heat sources at the other side [2] for a by declared standard given time.

This article deals with numerical and experimental study of thermal transfer between flame of a propan butan jet inside a designed insulated chamber and measured layered samples. Solving of a similar problem requires simultaneously application of several disciplines. At first, it is necessary to consider the standardization perspective, experimental conditions and evaluating of results are described in the several standards [3]. Indicating the description, conditions (Eq. 1), implementation and evaluation of tests or process criteria for final certification. An overall description of fire, combustion and behavior of structures exposed extreme heat loading provide authors in books like e.g [1].

${ }^{\mathrm{a}}$ Corresponding author: petr.kulhavy@tul.cz
In studying numerical modeling of a combustion processes and spreading of fire we could meet with the classical heat transfer $[2,4,5,6]$ and also with the transient turbulent flow models. There are several possible models based on the Navier-Stokes equations that is possible to use $[7,8]$. To their specific applications and description of using the so-called Eddy model that is most suitable for time unstable processes with amount of turbulence have written a lot of articles e.g. $[8,9,10]$. For proper adjustment of the model, especially in the definition of reaction media (air, gas), is very important come out of the fundamentals of chemistry, which defines the bonding forces $[6,11]$ and formed particles. The final model of gaseous components presented by particles participating in the reaction and their statistical distribution is described by $[12,13]$. So the whole problem goes beyond simple mechanical definitions of material properties and boundary group members (geometry).

\section{Materials and methods}

Each manufacturer has to tested its products and make a certification for fire resistance in the state testing laboratory or another certifying authority [14]. During the verification is the sample exposed to the defined in time increasing temperature [3]. The recorded values are integrity, temperature, radiation and level of insulation $[1,14]$. The test results are subsequently classified according to standard. The test results are subsequently classified, into categories according to their limit states that either prevent (EI) or reduce (EW) spreading of the fire at least for a declared time in minutes (15-90min) 
[3]. Standardized test is conducted in a special chamber where the process of fire simulating two LPG burners while the mass flow of fuel and oxidant could be regulated.

A homogenous distribution of the temperature in testing chamber is required for corresponding data of tests that are used for construction optimization of fire doors. Temperature distribution in the testing chamber near of sample was tested during measurement cycle. The temperature curve is prescribed with equation (1).

$$
\mathrm{T}=345 \log [8(t-20)+1]+20
$$

where $t$ is time in minutes and $T$ is required temperature in the chamber in Celsius degree.

\subsection{Fuels}

Gaseous fuels are chemically mixture of natural gases. Its composition depends on the site, but their properties are not different from another. Even though their composition could differ, their main properties are generally quite similar.

In our case the liquefied petroleum gas, that consisting mainly propane and butane has been used. Propane and butane is a colorless, easily volatile liquid, belong to the group of hydrocarbon gases from three to four carbon atoms per molecule (Tab. 1), which are obtained during the processing of crude oil and natural gas. The combination of these gases falls within group D - ie. Very high calorific value (over $20.93 \mathrm{MJ} / \mathrm{m}^{3}$ ). When for $0^{\circ} \mathrm{C}$ and $101.08 \mathrm{kPa}$ is the measured calorific value of about $46.1 \mathrm{MJ} / \mathrm{m}^{3}[1,15]$.

Table 1. LPG composition

\begin{tabular}{|l|cc|}
\hline Propan-butan & propane & butane \\
\hline Chemical formula & $\mathrm{C} 3 \mathrm{H} 8$ & $\mathrm{C} 4 \mathrm{H} 10$ \\
Molecular weight & 44,094 & 58,12 \\
\hline
\end{tabular}

Combustion meant a chemical physical process during which the combustible materials (gas) with an oxidant $\left(\mathrm{O}_{2}\right)$ are mixed. General stoichiometric equation of combustion hydrocarbon gas mixture $(2,3,4)$, which can be for propane butane used is according to [16] given:

$$
\mathrm{C}_{x} \mathrm{H}_{y}+{ }_{\mathrm{z}} \mathrm{O}_{2} \rightarrow x \mathrm{CO}_{2}+\frac{y}{2} \mathrm{H}_{2} \mathrm{O}
$$

When:

$$
z=x+1 / 4 y
$$

Which particularly for propane with oxygen is:

$$
\mathrm{C}_{3} \mathrm{H}_{8}+5 \mathrm{O}_{2} \rightarrow 3 \mathrm{CO}_{2}+4 \mathrm{H}_{2} \mathrm{O}
$$

\subsection{Fireproof samples}

For the first tests a layered sample, that provide us dependency between values and distribution of temperatures inside the chamber and at the outer side, was used. As the first prototypes combination of metal sheets and mineral foam were used (Fig. 1).

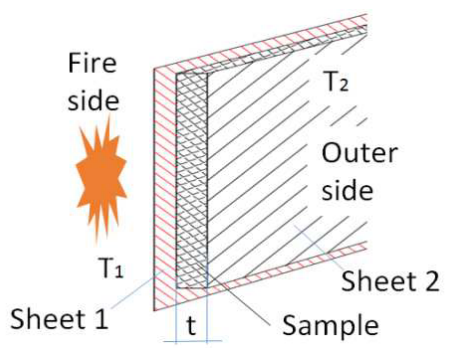

Figure 1. The measured layered sample

\subsection{Experimental device}

Set out the main geometry and dimensions was necessary to design the testing chamber (Fig. 2). Besides the isolated body these were primarily holes for the gas burners, adjustable air inlet (adjustable vents, fans, blowers) and simultaneously also the possibility of reduction the outgoing flue gases. Based on settings of all these conditions, we could distinguish between perfect and imperfect burning.

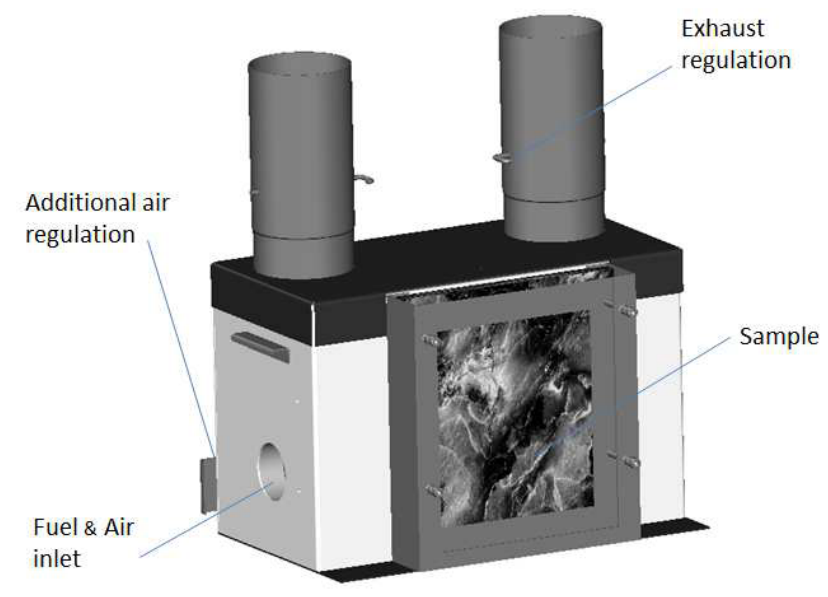

Figure 2. Scheme of the combustion chamber

When assuming the perfectly combustion it is possible according to [15] use the below approximated theoretical formula $(5,6)$.

$$
\begin{aligned}
& V_{\text {ssmin }}=K_{3} \frac{Q_{n}}{4186,7}+K_{4}\left[\mathrm{~m}^{3} / \mathrm{kg}\right], \quad\left[\mathrm{m}^{3} / \mathrm{m}^{3}\right] \\
& V_{\text {vsmin }}=K_{1} \frac{Q_{n}}{4186,7}+K_{2}\left[\mathrm{~m}^{3} / \mathrm{kg}\right], \quad\left[\mathrm{m}^{3} / \mathrm{m}^{3}\right]
\end{aligned}
$$

Where the index $\mathbf{v}$ is volume of air, $\mathbf{s}$ is volume of dry soot, and $\mathrm{K}_{\mathrm{i}}$ coefficient could be based on heat ratio $\mathrm{Q}$ observed in Tab 2.

Table 2. LPG coefficients

\begin{tabular}{|l|c|c|c|c|}
\hline \multirow{2}{*}{ Gaseous fuels } & $\mathrm{K} 1$ & $\mathrm{~K} 2$ & $\mathrm{~K} 3$ & $\mathrm{~K} 4$ \\
\cline { 2 - 5 } & {$\left[\mathrm{m}^{3} /\left(\mathrm{m}^{3} \mathrm{~kJ} / \mathrm{m}^{3}\right]\right.$} & {$\left[\mathrm{m}^{3} / \mathrm{m}^{3}\right]$} & {$\left[\mathrm{m}^{3} /\left(\mathrm{m}^{3} \mathrm{~kJ} / \mathrm{m}^{3}\right]\right.$} & {$\left[\mathrm{m}^{3} / \mathrm{m}^{3}\right]$} \\
\hline \hline $\begin{array}{l}\text { Qn }> \\
12,6 \mathrm{MJ} / \mathrm{m}^{3}\end{array}$ & 1,07 & 0,0 & 1,09 & 0,47 \\
\hline
\end{tabular}




\section{Experiments}

The combustion process in the chamber is accompanied by a flow of gas, air and combustion products. This process will affect the distribution of heat in the chamber and around the sample (Fig. 3). The temperature field on the surface of the sample facing towards the fire should not show significant variations with regard to position. Also the temperature in the chamber should meet a normalized temperature curve (Eq. 1).

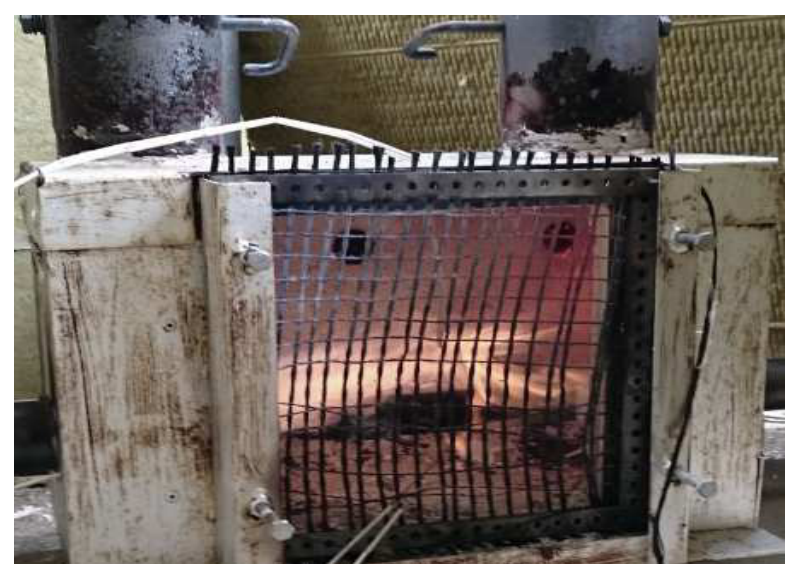

Figure 3. Example of the burning chamber without a sample

For this purpose the verification measurement that will show the distribution of temperature field in observed area was carried out. The measurement procedure is described below. Temperature was measured by four wire thermocouples type $\mathrm{K}$ that were placed symmetrically $5 \mathrm{~mm}$ from sample inner surface. Three thermocouples marked $\boldsymbol{a}, \boldsymbol{b}, \boldsymbol{c}$ were placed directly on outer side of sample. Data collection was carried out with modules Advantech Adam. For online monitoring of data software in JAVA script was prepared. A distance of thermocouples from the sample surface was approximately $5 \mathrm{~mm}$. After burner pre-heating outside of the chamber and the subsequent placement into the burner inlets the temperature inside the chamber was controlled by adjusting the gas pressure according to a prescribed curve. Recorded data from the individual thermocouples together with the control curve are shown in Fig. 4.

It could be seen that in the first minutes of measurement is not possible to ensure a desired course of the curve, which is due to the fact that thermocouples are very close to the flame or they lie on its edge. Maximal difference between $2-4$ minutes is less than $50^{\circ} \mathrm{C}$. It should be noted that deviation in first 5 minutes of test is not in the standard determined; there is only recommendation to achieve temperature near to the required temperature curve. In the interval from 5 minutes to the end of the measurement is the difference among individual thermocouples less than $30^{\circ} \mathrm{C}$ and about $15^{\circ} \mathrm{C}$ among thermocouples and required temperature curve. Higher temperatures are measured by thermocouples placed in higher position.

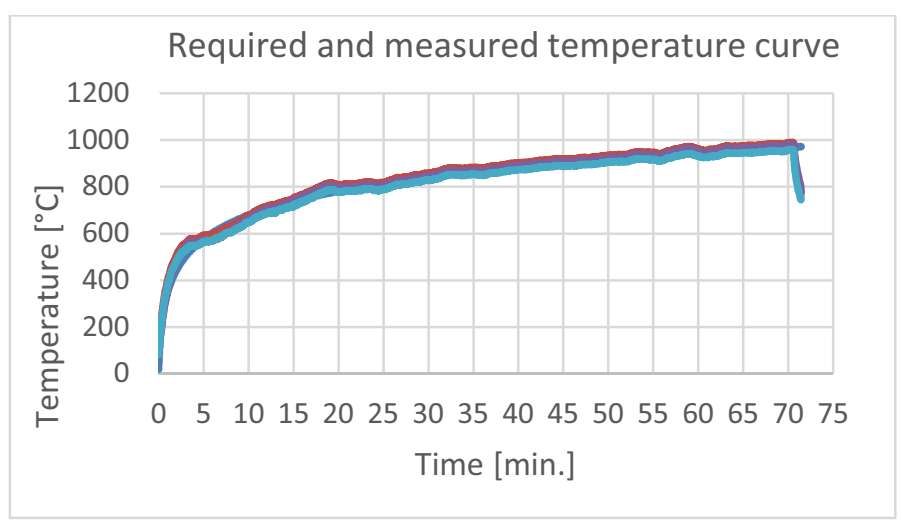

Figure 4. Temperature measured in the chamber

\subsection{Temperature on a sample}

Fig. 5 shows temperature on outer side of the sample. The thermocouple $\boldsymbol{b}$ is insert into a joint of door parts, where is not insulating layer. That is why a higher temperature is measured there.

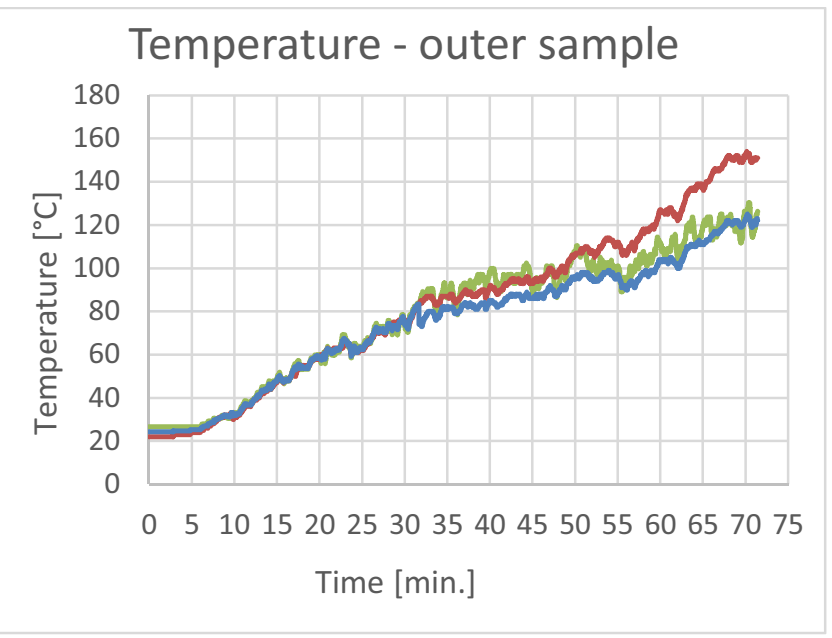

Figure 5. Temperature measured on outer surface of sample

\section{Numerical simulation}

Analytical or numerical solution of turbulent flow problems can be achieved using various levels of approximation, yielding more or less detailed descriptions of the flow. The easiest approach to modeling combustion is according to $[8,9]$ use semiempirical correlations, Moody's diagram or a more sophisticated method involves the use of Reynolds' averaging (7):

$$
\langle f\rangle=\frac{1}{T} \int_{t}^{t+T} f(\tau) d \tau
$$

where $f$ is the long time average of quantity and $\mathrm{T}$ the time interval - longer than all the time scales of the turbulent flow.

If the averaging is applied to the equations of motion, we obtain the Reynolds-averaged Navier-Stokes equations (RANS) that describe the evolution of the mean quantities $[7,17]$. 
The effect of turbulent fluctuations appears in a Reynolds stress term must be modeled to close the system [8, 9]. A very wide range of models for the Reynolds stresses is available - from simple algebraic models, K- $\varepsilon$ models to full or algebraic Reynolds stress closures [9].

Direct numerical simulations of turbulence are the most relevant approach to the solution of turbulent flows. The governing equations are discretized directly, and solved numerically. If the mesh is fine enough to resolve the smallest scales of motion, one can obtain an accurate three dimensional, time-dependent solution [7, 10]. Used software PyroSim (Fire Dynamics Simulator developed at NIST) solves the Navier-Stokes equations using the Large Eddy Simulation method. This solution is transient and will vary with time at any point $[9,10]$. In contrast, the Reynolds Averaged Navier-Stokes approach provides a single time averaged solution. Large-eddy simulations (LE) are a technique between the direct simulation of turbulent flows and the solution of the Reynolds-averaged equations. In LE the contribution of the large, energy carrying structures to momentum and energy transfer is computed exactly, and only the effect of the smallest scales of turbulence is modeled. LE simulations are based on the assumptions that the small scales are more isotropic, and less affected by the boundary conditions, than the large scales $[7,9,10]$.
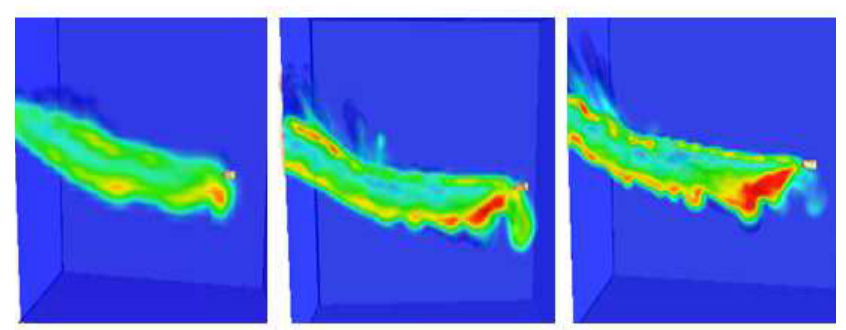

Figure 6. The combustion jet with different mesh size - 64, 512 a 1728 thousand cells (from left).

If a sufficiently refined mesh is used, FDS can accurately simulate a free jet. If the mesh refinement is too coarse, the solution will not observe turbulence in the shear layer that entertains the surrounding fluid and the predicted centerline velocity will not decay [9]. Generally, it is of course better to assess the quality of the mesh size in terms of nondimensional parameter, rather than an absolute size. Once mesh with size $5 \mathrm{~cm}$ could be adequate for case of spreading fire through a building but absolutely inaccurately for small sprinkler or jet like in our case. In FDS is the cell ratio used to describe relative mesh size. Due to the accuracy the cell ratio should not been bigger than $1 / 5$ of the characteristic fire diameter. According to [7] a mesh of even 1/16 the jet side is needed to obtain an reasonably accurate solution. This difference could be seen in the Fig. 6, where the same jet within different mesh cell ratio are shown. The cell number are $64 \mathrm{k}, 512 \mathrm{k}$ and $1728 \mathrm{k}$ elements. A twice smaller mesh mean decrease of the error $4 \mathrm{x}$, at the other side cause increase the time for solving 16x [10].

\subsection{Model definition}

The non-premixed combustion model with a mixture of propane-butane $(\mathrm{C} 2 \mathrm{H} 6, \mathrm{CH} 4)$ has been created. The LE theorem and the solution with considered baroclinic torque and the non ideal energy approach, that consider arising $\mathrm{CO}, \mathrm{H}_{2}$ and soot, has been used. According to [6] until our knowledge of the disposition and motion of the electrons in atoms and molecules are not complete, we cannot make a direct calculation of the forces played an important role among molecules in a gas. One of methods is to assume a definite laq of force and then by the kinetic theory deduce the appropriate lay of dependence of the viscosity of a gas on temperature. For this reason it is necessary in the material definition set also the Lennard-Jones potential [6, 11]. The most common expressions of the L-J potential are:

$$
V_{L J}=4 \varepsilon\left[\left(\frac{\sigma}{r}\right)^{12}-\left(\frac{\sigma}{r}\right)^{6}\right]=\varepsilon\left[\left(\frac{r_{m}}{r}\right)^{12}-2\left(\frac{r_{m}}{r}\right)^{6}\right]
$$

where $\varepsilon$ is a depth of the potential well, $\sigma$ is the distance at which the inter-particle potential is zero, $r$ is the distance between particles and $r_{\mathrm{m}}$ is the distance at which the potential reaches its minimum. At $r_{\mathrm{m}}$, the potential function has the value $-\varepsilon$. The distances are related as $r_{\mathrm{m}}$ $=2^{1 / 6} \sigma \approx 1.122 \sigma$.

These parameters can be fitted to reproduce experimental data or accurate chemistry calculations. Due to its computational simplicity, the Lennard-Jones potential is used extensively in computer simulations even though more accurate potentials exist. This intermolecular force may be attractive or repulsive, depending on the value of ,r“". From our point of view, using this parametr we could fit e.g. the „arising volume“" of flame. The L-J potential has only two parameters (A and $\mathrm{B}$ ) which determine the length and energy scales and may, without loss of generality, be set to unity. The potential is therefore unique, and cannot be fitted to properties of any real material [11]. For setting this parameter the studies of Heptane combustion $[9,10]$ has been used.

Three-dimensional flow was modelled by large Eddy model. Particle of defined gas, presented a moveable fragmented droplets ( 5000 per second), have been through nozzle sprayed into a model domain with defined volume flow rate $(\mathrm{L} / \mathrm{min})$, velocity $(\mathrm{m} / \mathrm{s})$ through a $12 / 10^{\circ}$ conical jet. In specific processes such as atomization or spraying a wide variety of mathematical and empirical distribution functions, such as the normal, log-normal or Rosin-Rammler distribution of particles is used (Fig. 7) [18]. The particles with median diameter $50 \mu \mathrm{m}$ via Rosin-Rammler log normal function have been distributed. This statistical model is suitable for description of materials composed of huge number of small particles like powder, emulsion and in our case small gas particles. More about using of this technique could be read there $[12,13,18]$. 


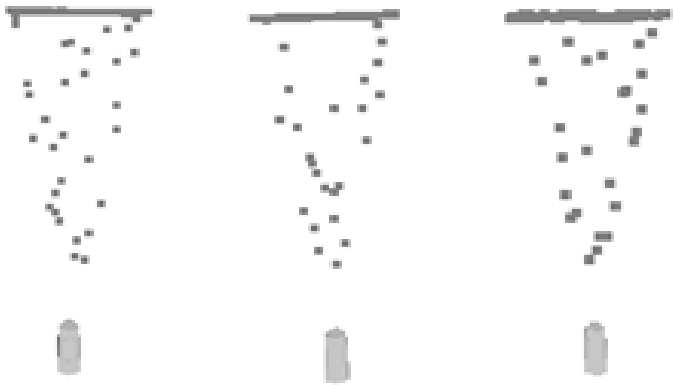

Figure 7. Constant, Rosin-Rammler and lognormal distribution of particles

At the other side, perhaps, due to the highly complicated model linked with a number of various boundary conditions and big concentration of the gas particles inside a relative small place (chamber), does not this parameter of used statistical approach seems to be as much important to the final results.

\subsection{Results of numerical simulation}

At the carried simulation (Fig. 8), we were primarily interested in the most accurate definition of the fire and subsequent in studying its effects on the tested layered sample (Fig. 1). The most important results for us is the inner heat (Fig. 9) is transferred through the sample and especially the temperature measured on the outside sheet (Fig. 10).
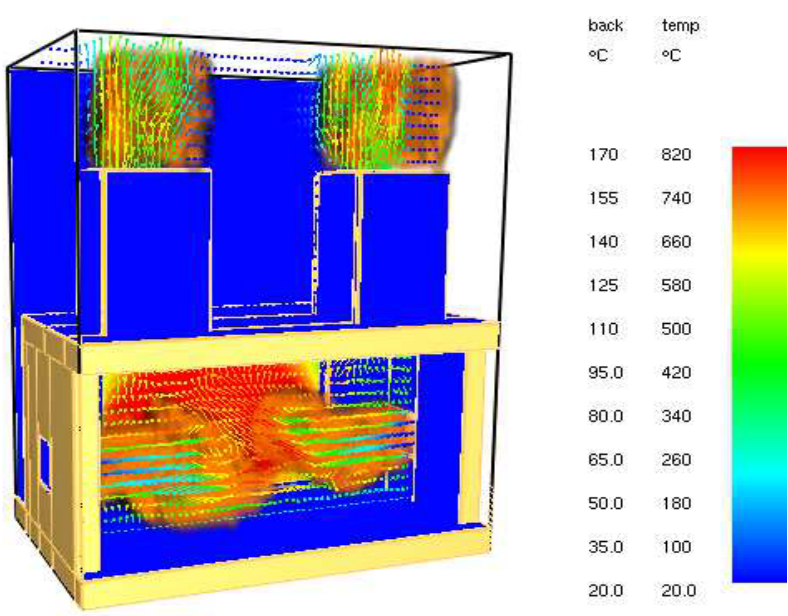

Figure 8. Temperature at the inner and outer sheets of the tested sample after $20 \mathrm{~min}$

The temperature in the outer side of sample in dependency on temperature in the chamber could be seen in Fig. 10 for a clearer idea how the heat energy going through the sample and future material comparison.

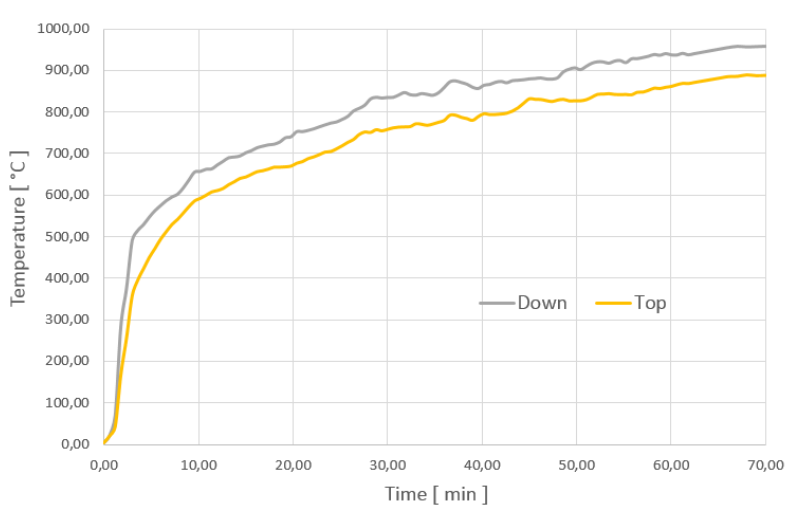

Figure 9. Graph of temperature in time - thermocouple near the top and the down side

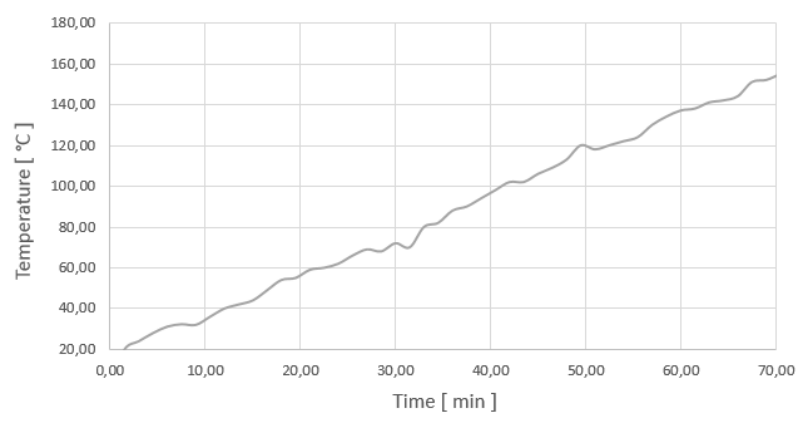

Figure 10. Temperature on the outer side of sample

\section{Results and discussion}

The experimental and numerical determination of the temperatures arising on the sample are in quite a good conformity. Furthermore, we can not adequately define the place where interaction of tested materials and e.g. the sample holder are imperfectly overlapped. In a real situation just there arising the significant concentration and dissipation of heat. Due to the large timeconsumption of the carried calculation, was also the whole body of the chamber considered as adiabatically inert only the front panel with the sample holder was adiabatic.

From the ordinary identifiable physical properties, which can be accurately determined experimentally it was in the fuel definition necessary to gone through the description of quantum chemical particles. At this moment, is due to the complexity of solved task necessary to rely on literature, which is based on empirically verified and tested data $[6,7,11,12]$. After a thorough study of this issue is using and adjusting of these parameters advisable to tweak the simulation nearer the experiment.

\section{Conclusion}

In the case of a fire inside building it is necessary to limit the spreading by the safe isolation fire zones, ie. The closure of fire doors. Just so we can safely protect people's health and reduce the loss on property. In the 
presented work the method for testing some new heatresistant materials was shown. Basis on the numerical model detailed idea about spreading of the gas mixture with air have been found. Using the software Pyrosim from the manufacturer Nist, the numerical model based on Large Eddy approach has been created. This software is one of the most appropriate tools for so complicated models, where various physical, chemical, thermal and hydrodynamic phenomenons are simultaneously solved. Work discussed mainly the possibilities of the materials (fuel, air, samples) definition. In comparison the simulation and experiment, we can talk about a relatively good agreement in the measured temperatures inside and outside the reference sample (inner and outer sheets). What remains, however problem for a similar simulation is modeling of the thermal degradation used materials over time. Use of simulation is therefore very suitable for direct determination of the moment and duration critical temperature values which must be coordinated with the knowledge obtained during the experiment. It can be also concluded that higher temperature on the beginning of the measurement has no influence of results, because higher temperature acts only short time.

In future work, efforts will be focused especially on definition of material models of tested insulating plates and improving their properties.

\section{Acknowledgements}

The results of this project VI20152018046 were obtained with co-funding from the Ministry of the Interior of the Czech Republic as part of targeted support from the project "Využití moderních metod modelování při vývoji a zkoušení protipožárních uzávěrů".

\section{References}

1. V. Kupilík, Stavebni konstrukce z požárního hlediska, Grada Publishing, (2006)

2. J. Egert, K. Frana, S. Simon, S. Wichmann, Heat Transfer Studies on Structured Metal Sheets. KMUTNB: IJAST, 9, (2016)

3. ISO 834-10:2014 Fire resistance tests - Elements of building construction, (2014)

4. P. Kulhavy, J. Kleckova, M. Petru and M. Havlicek. Optimization of the heat output, EPJ Web of Conferences, 114, 02061 (2016)

5. R. L. Webb, N. KIM, Principles of enhanced heat transfer, Taylor \& Francis, 2005.

6. J. E. Lennard-Jones, On the Determination of Molecular Fields, Proc. R. Soc. Lond. A, 106, (1924)

7. B. J. M. Giesen, et. al., Modelling and simulation of a jet fan, Env. Modelling and Software, 26, (2011)

8. U. Piomelli, LE and direct simulation of turbulent flows, University of Maryland, USA, (2001)

9. U. Piomelli, Large-eddy simulation: achievements and challenges, Progress in Aerospace Sciences, 35, (1999)

10. K. McGrattan, et al. Fire Dynamics Simulator Technical Reference Guide, 6, (2016)
11. D. Frenkel, B. Smit, Understanding Molecular Simulation, San Diego: Academic Press, 2, (2002)

12. H. Sis, G. Kelbaliyev, S. Chandler, Kinetics of drop breakage under turbulent conditions, Sci. Technol., 26 (2005)

13. E. Jurado, et al, Estimation of the distribution of droplet size, Colloids and Surfaces A: Physicochem. Eng. Aspects, 295 (2007)

14. ČSN EN 1363-1 - Testing of fire resistance - Part 1, ÚNMZ, Praha, (2000)

15. P. Kól, Combustion dynamics, Combustion proceses, awailable at: http://Spalovaciprocesy.wZ.cz/Statika horeni.html, (2011)

16. FDS-SMV Official Website. Fire Dynamics Simulator., USA: National Ins. of Standards and Technology.

17. K. Akselvoll, P. Moin, Large-eddy simulation of turbulent conned coannular jets. J. Fluid Mech., (1996)

18. A. H. Lefebvre, Atomization and Spray, Hemisphere Publishing, Washington, (1989) 